\title{
Innovative Gen-II/III and research reactors' fuels and materials
}

\author{
Pietro Agostini ${ }^{1,{ }^{*}}$, Marco Utili ${ }^{1}$, Konstantza Lambrinou ${ }^{2}$, Heikki Keinänen ${ }^{3}$, \\ Paivi Karjalainen-Roikonen ${ }^{3}$, and Mariana Arnoult Ruzickova ${ }^{4}$ \\ ${ }^{1}$ ENEA-FSN-ING Division, C.R. Brasimone 40032, Camugnano, Italy \\ 2 NMS Institute, SCK•CEN, Boeretang 200, 2400 Mol, Belgium \\ 3 BA2505 Structural Integrity, VTT Technical Research Centre of Finland Ltd., Kivimiehentie 3, Espoo, Finland \\ ${ }^{4}$ Power Engineering Technologies Department, Centrum výzkumu Řež, Hlavní 130, 25865 Husinec Rež, Czech Republic
}

Received: 5 April 2019 / Accepted: 16 June 2019

\begin{abstract}
This manuscript presents important material challenges regarding innovative Gen-II/III nuclear systems and research reactors. The challenges are discussed alongside the key achievements so far realised within the framework of 4 EU-funded projects: H2020 IL TROVATORE, FP7 MULTIMETAL, FP7 MATTER and FP7 SCWR-FQT. All the four Projects deal with innovative researches on materials to enhance the safety of nuclear reactors. IL TROVATORE proposes new materials for fuel cladding of PWR reactors and tests in order to really find out an "Accident Tolerant Fuel" (ATF). MULTIMETAL focused on optimization of dissimilar welds fabrication having considered the field performances and dedicated experiments. MATTER carried on methodological and experimental studies on the use of grade 91 steel in the harsh environment of liquid metal cooled EU fast reactors. SCWR-FQT focused on fuel qualification of Supercritical Water Reactor including the selection of the better material to resist the associated high thermal flux.
\end{abstract}

\section{Introduction}

The 2011 Fukushima Daiichi event demonstrated the need for improved nuclear safety. In the present work, which reports activities performed within four different EU Projects, the approach to enhance nuclear safety takes into consideration only the materials studies. In IL TROVATORE EU Project the focus was dedicated to new fuel cladding materials, able to resist the very high temperatures which are achieved during the Loss Of Coolant Accident of a PWR Reactor. These new materials are claimed to prevent the release of fission products so driving to the development of accident-tolerant fuels (ATFs). ATFs are expected to overcome the inherent technical shortcomings of the standard zircaloy/ $\mathrm{UO}_{2}$ fuels, thus preventing the fuel cladding material failure and subsequent release of radioactive fission products to the power plant containment and the environment [1]. The main objective of IL TROVATORE ("Innovative cladding materials for advanced accident-tolerant energy systems") is to optimise promising ATF cladding material concepts for Gen-II/III light water reactors

\footnotetext{
* e-mail: pietro.agostini@enea.it
}

(LWRs) and validate them in an industrially relevant environment via a dedicated neutron irradiation in PWRlike water.

Besides high temperature peaks, another important reason of structural failure in nuclear reactors is represented by the material embrittlement, especially under neutron flux exposure. The dissimilar metal welds represent, by operational experience, a typical location of brittle rupture of components. The first objective of the FP7 project MULTIMETAL ("Structural performance of multi-metal component") was to collect relevant information from the field experience, whereby typical locations of dissimilar metal welds (DMWs) in both Western and Eastern LWRs were identified, and their characteristics as well as applicable performance assessment methods considered. The analysis of ductile failure processes was supported by numerical methods considering ageingrelated phenomena and realistic stress distributions in the weld area. Modelling was supported by a comprehensive material test program and procedures for measuring the fracture toughness of DMWs.

In liquid metal cooled fast reactors, besides the high temperature and the brittle rupture, also corrosion attack has to be considered as a third motivation for failure of structural materials. The MATTER EU Project took into consideration all these failure causes through extensive 
technological research on grade 91 materials for their applications in ESNII reactors. To this purpose, specific material testing procedures were developed for the ASTRID and MYRRHA projects and the design rules were proposed with particular attention to ferritic/ martensitic $(\mathrm{f} / \mathrm{m})$ tempered steel.

The corrosive environment and the high temperature are also considered as the most relevant failure causes for the Supercritical Water Reactor. Although SCWR case is different from liquid metal cases, similar material studies to identify the best candidate material were performed in SCWR-FQP Project. The major challenges for the SCWRFQP Project were to develop a viable core design, accurately estimate the heat transfer coefficient and develop materials for the fuel and core structures.

\section{IL TROVATORE}

IL TROVATORE (ID: 740415) is an ongoing H2020 project scheduled to run between $01 / 10 / 17$ and $31 / 03 / 22$. The EU contribution is $4999999,25 €$, and the project coordinator is SCK•CEN, the Belgian Nuclear Research Centre. IL TROVATORE is an international collaboration that combines academic excellence with strong industrial support, boasting 30 beneficiaries across 3 continents (i.e., 28 beneficiaries from Europe, 1 from the USA, and 1 from Japan). IL TROVATORE focuses primarily on the following innovative accident tolerant fuel (ATF) cladding material concepts: (a) SiC/SiC composite clads (different designs) $[2,3]$, (b) MAX phase-coated [4] and (c) oxidecoated commercial zircaloy clads [5], (d) Gepulste ElektronenStrahl Anlage (GESA) surface-modified commercial zircaloy clads [6], and (e) oxide-dispersed-strengthened (ODS) $\mathrm{FeCrAl}$ alloy clads [7]. Figure 1 shows images associated with the innovative cladding materials which are proposed and fabricated within the Project IL TROVATORE; more details on these material concepts have been presented elsewhere [8]. Since the 1st reporting period (18 months) of IL TROVATORE has just finished and most of the technical achievements have not yet been published, the present document will not include data pertaining to the S\&T status of this project. However, various (open access) publications have already appeared in high-impact peer-reviewed journals, such as Scientific Reports, Inorganic Chemistry, etc. The activities in IL TROVATORE are thematically grouped in 3 domains: DM1-processing; DM2-characterisation of non-irradiated materials; and DM3-characterisation of irradiated materials and predictive modelling activities. A fourth domain DM4 encompasses standardisation, exploitation of results, and dissemination and communication.

\section{MULTIMETAL}

MULTIMETAL (ID: 295968) was active in the period $01 / 02 / 12$ to $31 / 01 / 15$. The EU contribution was $1683480,98 €$, and the project coordinator was VTT, Finland. FP7 MULTIMETAL involved 8 beneficiaries and was organised into the 8 work packages (WPs). The approach to studies of dissimilar metal welds (DMW) was carried out through dedicated actions. The first step of the project was to gather relevant information from field experience. Typical locations of DMWs in Western and Eastern type LWRs were identified, together with their physical and metallurgical characteristics, as well as applicable structural integrity assessment methods. The collection of relevant field information was followed by computational structural integrity assessment analyses of DMWs for dedicated test configurations and real cases.

These analyses involved simple engineering methods and numerical analyses. Ageing-related phenomena and realistic stress distributions in the weld area were considered. The computational analyses were supported by a comprehensive materials test program. Its aim was to develop a procedure for measuring the fracture toughness of DMWs. The project promoted the development of a common understanding for structural integrity assessment of DMWs in existing and future NPPs in EU member states. All DMW design variants showed high resistance to crack growth under the investigated conditions.

FP7 MULTIMETAL recommends the use of compact tension (CT) specimens (sub-sized, if necessary) for fracture toughness characterization of DMWs (Fig. 2).

\section{MATTER}

MATTER (ID: 269706) was active in the period 01/01/11 to $31 / 12 / 14$. The EU contribution was $5993919 €$, and the project coordinator was ENEA, Italy. FP7 MATTER involved 27 beneficiaries from 13 countries.

The main objective of the FP7 project MATTER ("MATerials TEsting and Rules") was to conduct ESNII reactor design research in the field of materials, in particular for the accelerator-driven systems (ADS) ASTRID and MYRRHA. At the beginning of MATTER, the status of ASTRID and MYRRHA projects was identified as well as the requirements set by the two Projects in terms of researches to be dedicated to the employment of grade 91 steel. In the course of MATTER significant efforts were dedicated to new test procedures. Namely R\&D activities were carried out in order to standardize liquid metal corrosion and mechanical tests on miniaturized specimens.

ESNII reactors are designed to work at high temperatures and high mechanical stress. The reference standards that are used in Europe for these projects, in particular the French RCC-MRx, refer mainly to the AISI 316L steel, the high-temperature characteristics of which are very different from those of grade 91 steels. Since the grade 91 steel softens under cyclic load and under creep conditions, it was necessary, in the course of MATTER, to conceive and conduct specific mechanical tests in order to draw the specific performance rules of the steel in terms of creepfatigue, ratchetting and negligible creep.

For ratchetting, the work in FP7 MATTER included the development of viscoplastic constitutive models for more detailed simulation under more general conditions as well as the development and validation of an efficiency diagram in accordance with RCC-MRx approach. 

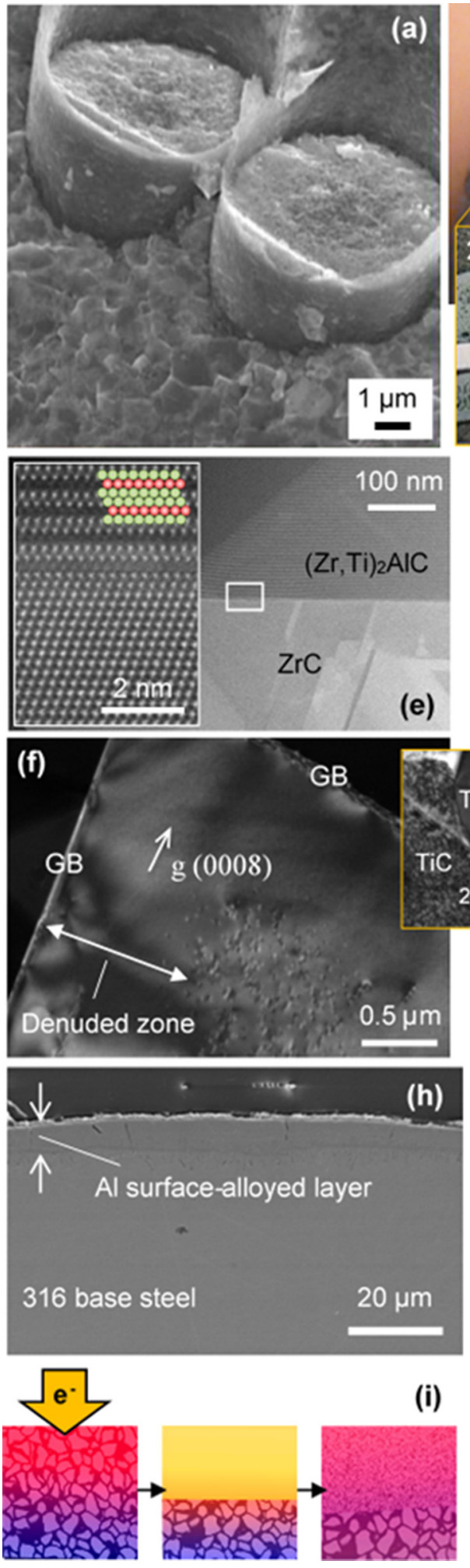
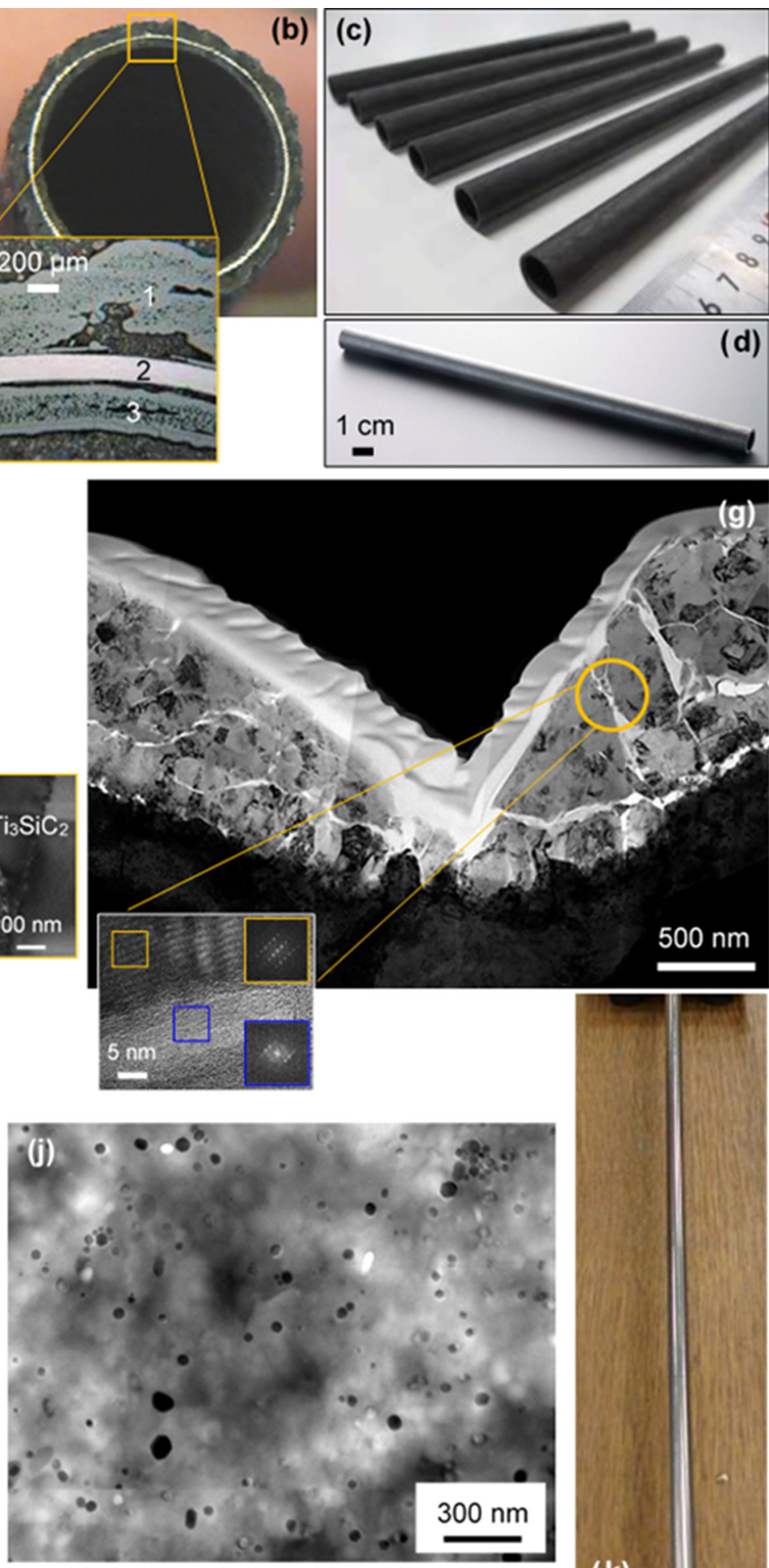

(k)

Fig. 1. (a-d) SiC/SiC composite clads: (a,c) DEMO-NITE SiC/SiC fracture surface and tubes; (b,d) CEA "sandwich" SiC/SiC crosssection and tube. (e) STEM image of a $(\mathrm{Zr}, \mathrm{Ti})_{2} \mathrm{AlC}$ MAX phase grain next to a ZrC "impurity" grain. The magnified inset is a STEM image of the $(\mathrm{Zr}, \mathrm{Ti})_{2} \mathrm{AlC} / \mathrm{ZrC}$ interface. (f) Neutron-irradiated $\mathrm{Ti}_{3} \mathrm{SiC}_{2}\left(\sim 735^{\circ} \mathrm{C}, 3.4 \mathrm{dpa}\right)$ : defect-denuded zones are established next to grain boundaries (GBs) acting as potent defect "sinks". The magnified inset shows more damage in the "impurity" TiC grain than in $\mathrm{Ti}_{3} \mathrm{SiC}_{2}$. (g) TEM images of a nano-impacted, ion-irradiated (150 dpa) $\mathrm{Al}_{2} \mathrm{O}_{3}$ coating: the crack-like features are filled with vitreous matter. (h) GESA Al surface-alloyed $316 \mathrm{~L}$ steel exposed to liquid $\mathrm{LBE}\left(10000 \mathrm{~h}, 600^{\circ} \mathrm{C}, C_{\mathrm{O}} \approx 10^{-6}\right.$ mass $\%$ ). (i) GESA surface modification by an intense pulsed electron beam: volumetric heating $\rightarrow$ formation of a melt layer $\rightarrow$ restructured surface layer. (j) TEM image of a Fe-20Cr-5Al-0.5Ti-0.5 $\mathrm{Y}_{2} \mathrm{O}_{3}$ alloy with nano-sized dispersoids. (k) Fe-14Cr ODS tube produced by CEA. 


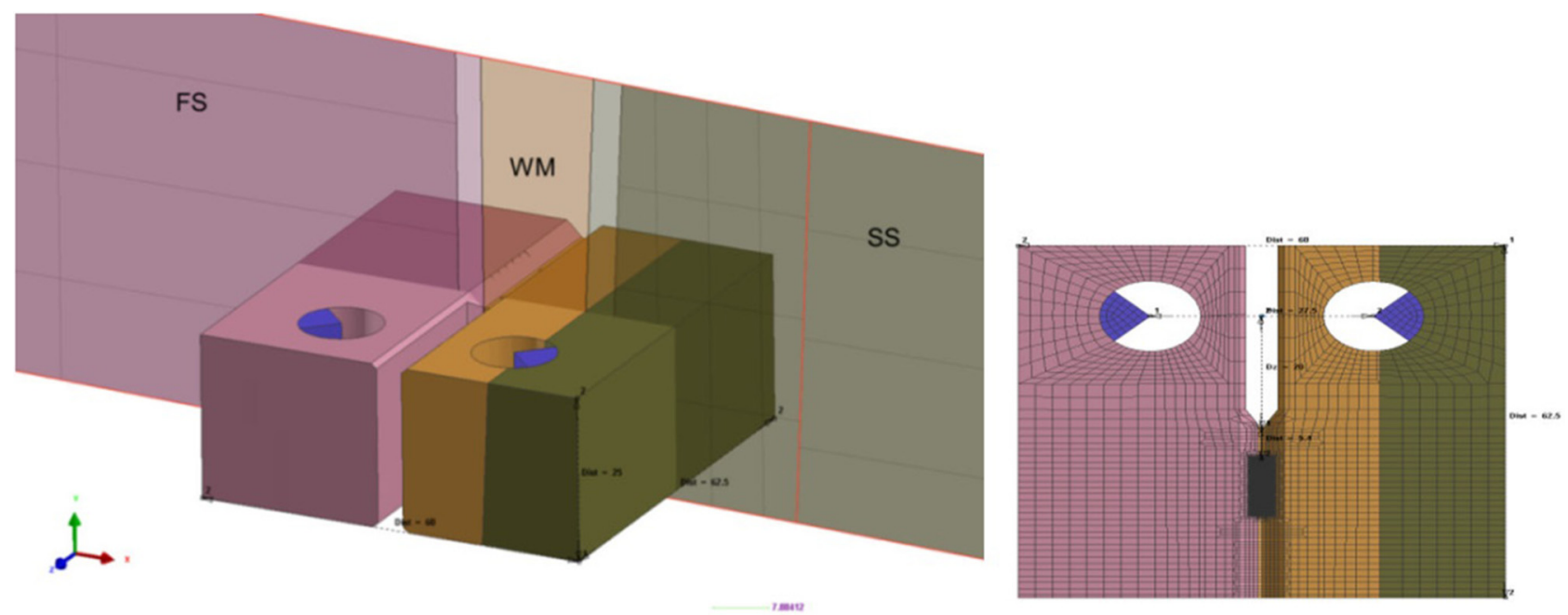

Fig. 2. Position and meshing of a CT25 specimen (MU1).
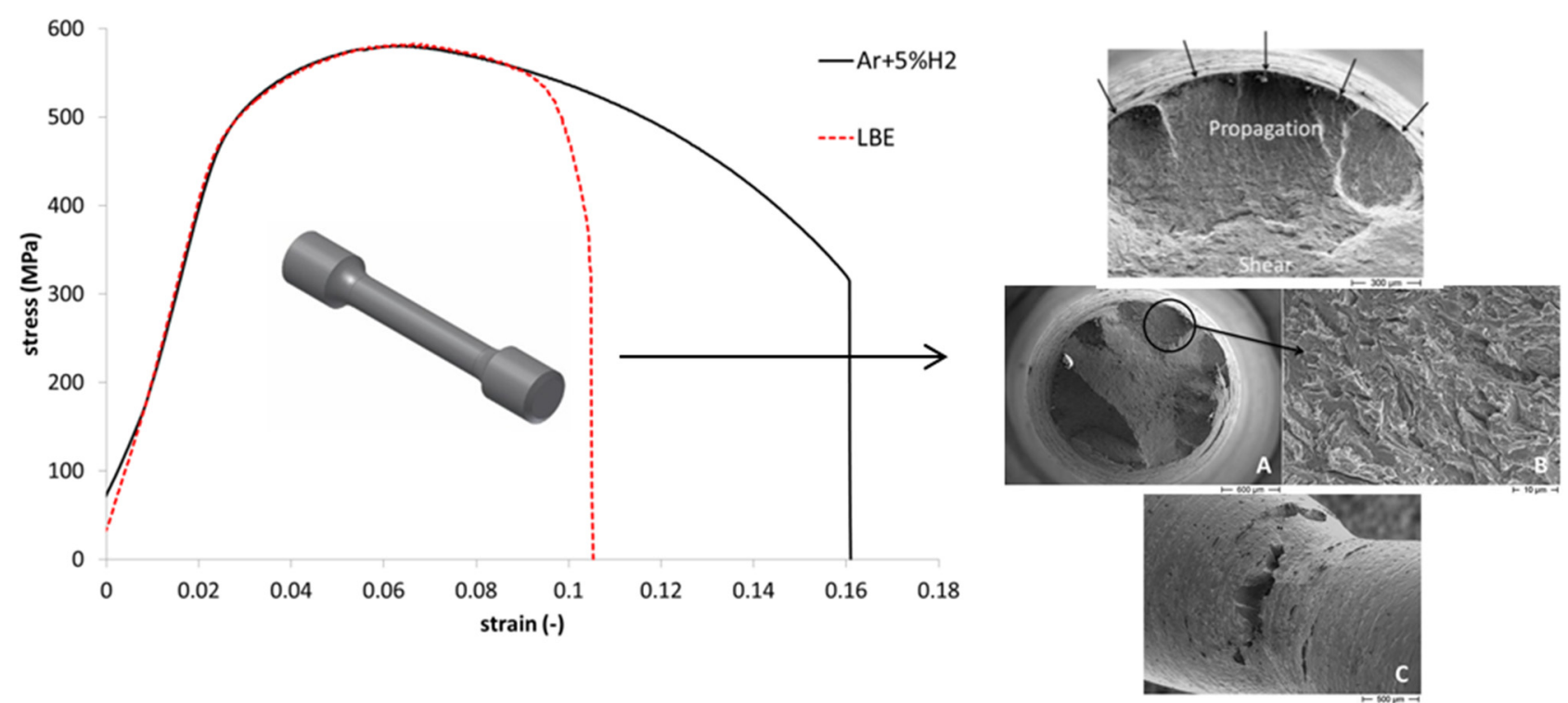

Fig. 3. Stress-strain curves of a T91 f/m steel tested in tension in $\mathrm{Ar}+5 \% \mathrm{H}_{2}$ and oxygen-poor $\left(C_{\mathrm{O}} \approx 10^{-9}-10^{-10}\right.$ mass $\left.\%\right)$ static liquid LBE. Both tests were conducted at $350^{\circ} \mathrm{C}$ under an applied strain rate of $5 \times 10^{-5} \mathrm{~s}^{-1}$. The specimen tested in LBE was pre-exposed at $450^{\circ} \mathrm{C}$ in low-oxygen liquid LBE. The fracture surface of the specimen tested in LBE (A) shows areas that suffered quasi-cleavage (B) failure. Also, the inspection of the specimen necking region shows the formation of numerous side cracks (C).

The proposed design rules for ratchetting, creep-fatigue and negligible creep were submitted to review by AFCEN for inclusion in RCC-MR, as probationary rules in a first stage. The designers of Gen-IV reactors need to demonstrate that non-replaceable components retain their integrity and reliable operation for at least $60 \mathrm{yr}$, therefore long-term degradation mechanisms, including thermal ageing, irradiation and environmental effects from heavy liquid metal were addressed.

Tensile tests in lead-bismuth eutectic (coolant of MYRRHA) demonstrated that P91 steels are susceptible to liquid metal embrittlement as shown in Figure 3. The consequent decision by the MYRRHA designers was to exclude this material from the construction of structural components.
The integrity of welds is a key issue for the design of all ESNII reactors. The development of fatigue weld factors, as well as the assessment of new filler materials and welding procedures, is of direct relevance for ESNII.

In MATTER, fabrication efforts were dedicated to oxide dispersed strengthened (ODS) steels based on grade 91 composition, in order to enhance the EU knowledge in this sector.

\section{SCWR-FQT}

In 2011, the FP7 SCWR-FQT ("Supercritical Water Reactor - Fuel Qualification Test") project started. This project was active in the period $01 / 01 / 11$ to $31 / 12 / 14$. 


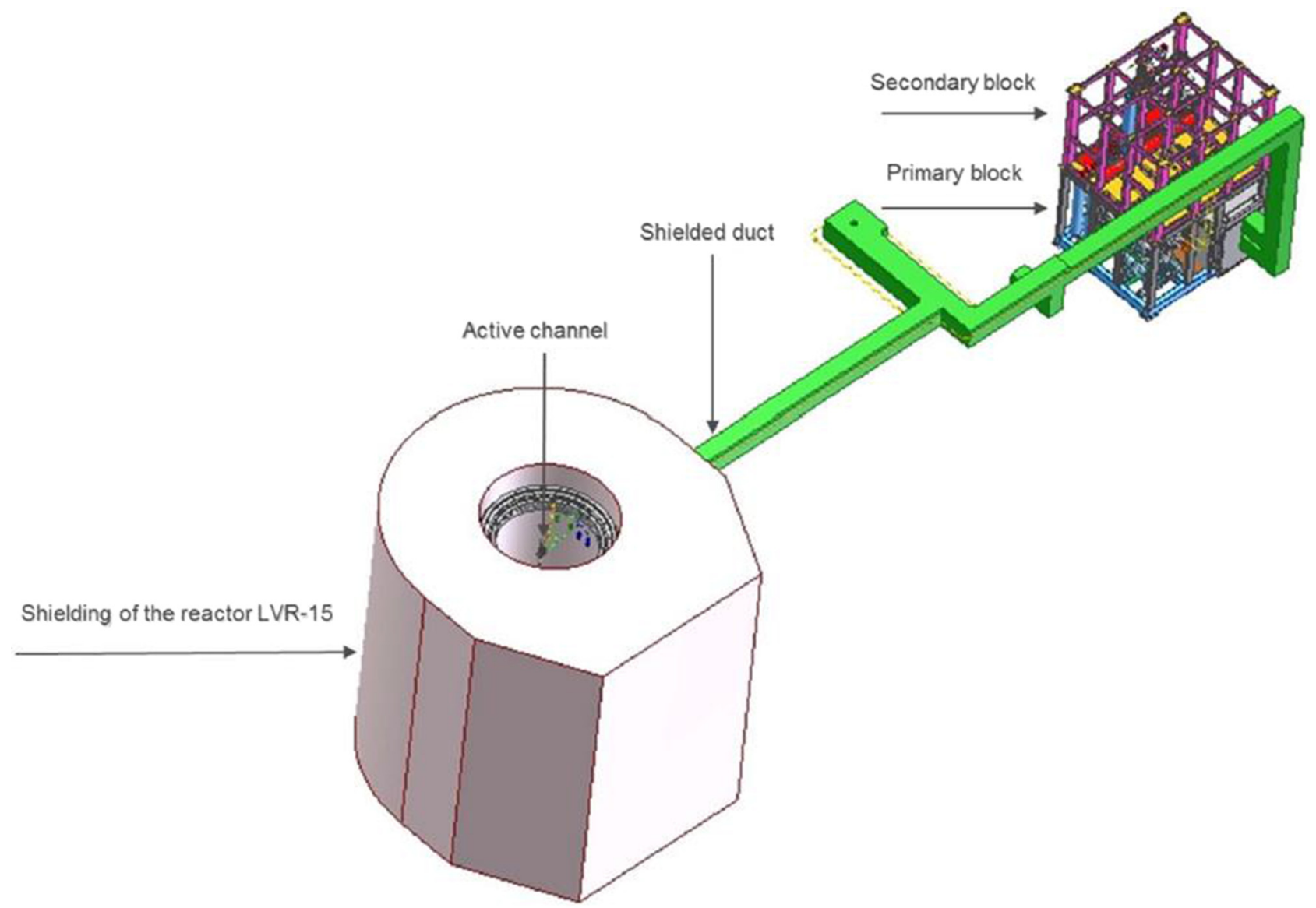

Fig. 4. SCWL-FQT loop and LVR-15 reactor [11].

The EU contribution was $1500000 €$, and the project coordinator was the Centrum Výzkumu Rež (CVR), Czech Republic. FP7 SCWR-FQT involving 7 European partners and 9 partners from China.

The FP7 SCWR-FQT project was built as 3 interconnected work packages that ran in parallel: the first work package contained all the design work and analyses of the fuel qualification test (FQT) facility; the second one dealt with the design of a similar, electrically heated test section that served for pre-qualification of the test section and that was designed and built in China; finally, the third work package dealt with the choice of a suitable cladding material, including necessary corrosion and mechanical tests. The objectives of the project were to make significant progress towards the design, analysis and licensing of the Fuel Qualification Test (FQT) facility cooled with supercritical water (Fig. 4) in the research reactor LVR15. Test of the fuel assembly was addressed with the following concept: a pressure tube was placed instead of a fuel assembly in the LVR-15 reactor. It contained 4 fuel rods with $8 \mathrm{~mm}$ diameter and $9.44 \mathrm{~mm}$ pitch, similar to the HPLWR assembly concept [10], inside a square assembly box. The heated length was limited to $600 \mathrm{~mm}$ to match the core height of the reactor.

Final design and results of analyses of the test section, including the supercritical water loop, formed the basis of the licensing documents for the Czech regulator. Data from the operation of the electrically heated test section should serve both for pre-qualification operation as well as for validation of the codes used for analyses. Corrosion and mechanical data became available for the selected materials and a choice of the cladding materials was made during the project.

\section{Achieved results}

IL TROVATORE Project is not yet concluded, nevertheless the interim achievements are the fabrication and laboratory testing of six different candidate materials which are proposed as PWR fuel clads in order to resist the very high temperature experienced by the core during a LOCA transient.

The FP7 project MULTIMETAL confirmed that in different metal welds, the most critical zone, in terms of fracture, lies in a narrow band around the weld/low-alloysteel interface.

The characterization of local tensile properties was a key issue for analysing the toughness tests as well as the tests on weld mock-ups. New procedures were proposed for tensile testing.

In MATTER the standardization of liquid metal corrosion has led to test procedures and to the design of a test device currently used, within EERA JPNM, by all 
institutions contributing to corrosion tests in static heavy liquid metals (lead, $\mathrm{Pb}$, and lead-bismuth eutectic, LBE). In terms of impact, the experimental evidence of the insufficient fracture toughness of T91 f/m steels after prewetting with LBE, determined its exclusion from the construction of MYRRHA load-bearing components.

In SCWR-FQT, the final design, the material selection and the results of analyses of the test section, including the supercritical water loop, formed the basis of the licensing documents for the Czech regulator.

\section{Dissemination and capitalization of the knowledge}

Within IL TROVATORE, a series of six educational \& training activities are planned. The first one in this series was the International Workshop on MAX Phases for Harsh Environments, which provided hands-on training sessions on powder metallurgy and electron microscopy techniques to PhD students. In order to maximise the open access and re-use of its results, IL TROVATORE participates in the H2020 Open Research Data Pilot without jeopardising the commercial exploitability of the achieved innovation, since a strict set of rules has been established in the Consortium Agreement to protect foreground intellectual property rights (IPRs). The openly accessible data sets, codes, etc., are preserved in the Zenodo repository. IL TROVATORE makes a conscious effort to make its research data findable, accessible, interoperable and reusable (FAIR) [9].

Also, in MULTIMETAL a training course and exchange program for young scientists, based on outcomes and experience gained within the area of weld fracture toughness testing was organised.

At the end of the MATTER project, a total of 321 validated data sets for P91 and AISI 316 steels had been uploaded by 8 project partners to the JRC web-enabled database MatDB. The uploaded data included: load- and strain-controlled low-cycle fatigue, small punch tests, uniaxial creep, uniaxial tensile, creep crack growth and fracture toughness data. Two international workshops and two summer schools were organized. A special edition of Journal of Nuclear Material was issued to report the most relevant MATTER outcomes in related articles [12].

Within SCWR-FQT a broader communication route was established through informing the wider scientific community and involving students of Doctorate programs in the R\&D work. Numerous papers have been presented at Conferences, topical Meetings and Workshops, such as:

International Symposium on Supercritical WaterCooled Reactors; International Topical Meeting on Nuclear Thermal Hydraulics, Operation and Safety; International Topical Meeting on Nuclear Reactor Thermal Hydraulics; Nordic Nuclear Materials Forum for GenIV Reactors; 10th SCWR Information Exchange Meeting; International Conference on Nuclear Engineering; Joint HZDR \& ANSYS Conference; The European Nuclear Conference; Siempelkamp Workshop "Kompetenzerhaltung in der Kerntechnik" ("Maintaining Competence in the Nuclear Technology"); European conference on Euratom research and training in reactor systems; European
Research Reactor Conference; STAR Global Conference; and Pacific Basin Nuclear Conference; Annual Meeting on Nuclear Technology.

Results from the project were also published as articles in the following peer-reviewed journals: Progress in Nuclear Energy; International Journal of Heat and Mass Transfer; Nuclear Engineering and Design; Safety of Nuclear Energy (Journal published by the Czech regulator - in Czech).

At Karlsruhe Institute of Technology (KIT), two PhD theses have been completed within the framework of this project.

\section{Conclusions and recommendations}

All the four projects addressed European studies to prevent structural material failures in reactors.

IL TROVATORE focuses on qualification in relevant environment of fuel clads able to resist the very high temperature subsequent to loss of coolant accident of PWR's.

MULTIMETAL addressed the brittle fracture of dissimilar metal welds through field experience, fracture toughness tests and simplified modelling. It is recommended to use the ASTM 1820 standard CT-specimens to assess fracture toughness of DMWs, where the location of the notch must be at the fusion line $( \pm 0 \mathrm{~mm})$ between ferritic heat-affected zone and the Ni-base alloy for Ni-based narrow-gap.

MATTER Project addressed all the typical failure causes of ferritic/martensitic steel in liquid metal cooled fast reactors. Besides the high temperature and the brittle rupture, also corrosion attack and many others were considered. The unfavourable outcomes of grade 91 steel, triggered the need to develop so-called "mitigation measures" to limit the degradation of materials from heavy liquid metals. Subsequent EU projects, such as the H2020 GEMMA and H2020 IL TROVATORE (side-activity), are studying promising "mitigation measures" that might be applicable to heavy liquid metal environments.

Corrosion and high temperature are also considered as the most relevant failure causes for the Supercritical Water Reactor. In SCWR-FQP the best performing material for fuel clads and core structures was selected. The study on consequences of a pressure tube rupture performed in the electrically heated test section allowed preparing the recommendations to be included in the safety analysis for the "Fuel Qualification Test with Supercritical Water".

\section{References}

1. E. Lahoda, L. Hallstadius, F. Boylan, S. Ray, What should be the objective of accident tolerant fuel? in American Nuclear Society 2014 Annual Meeting, Nuclear Fuels and Structural Materials, Reno, NV, USA, 17 June 2014, Paper 10231

2. A. Kohyama, Y. Kohno, H. Kishimoto, J.S. Park, H.C. Jung, Industrialization of advanced $\mathrm{SiC} / \mathrm{SiC}$ composites and $\mathrm{SiC}$ based composites; Intensive activities at Muroran Institute of Technology under OASIS, IOP Conf. Ser.: Mater. Sci. Eng. 18, $202002(2011)$

3. J.C. Brachet, C. Lorrette, A. Michaux, C. Sauder, I. Idarraga-Trujillo, M. Le Saux, M. Le Flem, F. Schuster, 
A. Billard, E. Monsifrot, E. Torres, F. Rebillat, J. Bischoff, A. Ambard, CEA studies on advanced nuclear fuel claddings for enhanced Accident Tolerant LWRs Fuel (LOCA and beyond LOCA conditions), in Proc. Fontevraud 8: Contribution of Materials Investigations and Operating Experience to LWRs' Safety, Performance and Reliability, Avignon, France, 14-18 September 2014, INIS Vol. 46, Report No. INIS-FR-15-0424, Ref. No. 46081720, IAEA-INIS, 2015

4. M.W. Barsoum, MAX phases - properties of machinable ternary carbides and nitrides (Wiley-VCH Verlag $\mathrm{GmbH} \&$ Co. KGaA, Weinheim, Germany, 2013)

5. F. García Ferré, A. Mairov, L. Ceseracciu, Y. Serruys, P. Trocellier, C. Baumier, O. Kaïtasov, R. Brescia, D. Castaldi, P. Vena, M.G. Berghi, L. Beck, K. Shridharan, F. Di Fonzo, Radiation endurance in $\mathrm{Al}_{2} \mathrm{O}_{3}$ nanoceramics, Sci. Rep. 6, 33478 (2016)

6. V. Engelko, B. Yatsenko, G. Müller, H. Bluhm, Pulsed electron beam facility (GESA) for surface treatment of materials, Vacuum 62, 211 (2001)

7. K.A. Terrani, S.J. Zinkle, L.L. Snead, Advanced oxidationresistant iron-based alloys for LWR fuel cladding, J. Nucl. Mater. 448, 420 (2014)
8. K. Lambrinou, M. Verwerft, J. Vleugels, A. Weisenburger, C. Lorrette, Y. De Carlan, F. Di Fonzo, M.W. Barsoum, A. Kohyama, Innovative accident-tolerant fuel cladding materials: the H2020 IL TROVATORE perspective, in Proc. of the 2017 Water Reactor Fuel Performance Meeting (WRFPM 2017), Jeju Island, Korea, 10-14 September 2017, pp. 1-10, paper F-250-PD1

9. M.D. Wilkinson et al., The FAIR guiding principles for scientific data management and stewardship, Sci. Data 3, 160018 (2016)

10. T. Schulenberg, J. Starflinger, P. Marsault, D. Bittermann, C. Maráczy, E. Laurien, J.A. Lycklama, À. Nijeholt, H. Anglart, M. Andreani, M. Ruzickova, A. Toivonen, European supercritical water-cooled reactor, Nucl. Eng. Des. 241, 3505 (2011)

11. M. Ruzickova, A. Vojacek, T. Schulenberg, D. Visser, R. Novotny, A. Kiss, C. Maráczy, A. Toivonen, Supercritical water reactor-fuel qualification test: overview, results, lessons learned, and future outlook, J. Nucl. Eng. Radiat. Sci. 2, 011002 (2016)

12. M. Utili, Special Section on MATTER - MATerials TEsting and Rules, J. Nucl. Mater. 472 (2016)

Cite this article as: Pietro Agostini, Marco Utili, Konstantza Lambrinou, Heikki Keinänen, Paivi Karjalainen-Roikonen, Mariana Arnoult Ruzickova, Innovative Gen-II/III and research reactors' fuels and materials, EPJ Nuclear Sci. Technol. 6, $41(2020)$ 